\title{
Prognostic value of differential expression of Laminin-5 $\gamma 2$ in oral squamous cell carcinomas: Correlation with survival
}

\author{
A. GASPARONI ${ }^{1}$, M. DELLA CASA ${ }^{1}$, L. MILILLO ${ }^{2}$, G. LORENZINI $^{1}$, \\ C. RUBINI ${ }^{3}$, R. URSO $^{1}$ and L. LO MUZIO ${ }^{2}$ \\ ${ }^{1}$ Dipartimento di Farmacologia 'G. Segre' - Sezione di Anatomia, Università degli Studi di Siena, Siena; \\ ${ }^{2}$ Dipartimento di Scienze Chirurgiche, Università degli Studi di Foggia, Foggia; \\ ${ }^{3}$ Istituto di Anatomia Patologica, Università Politecnica delle Marche, Ancona, Italy
}

Received April 11,2007; Accepted May 25, 2007

\begin{abstract}
In oral squamous cell carcinomas of the head and neck, Laminin-5 $\gamma 2$ has been associated with tissue invasion, lymph node metastasis and histopathological grading. In the present study, we compared the expression of the subunit $\gamma 2$ of Laminin-5 under normal, dysplastic and invading epithelia in 65 biopsies previously diagnosed for oral squamous cell carcinoma. The number of $\gamma 2$-positive cells were analyzed in relation to patients' survival, tumor grading, size of the lesion, TNM stage, histopathological pattern of invasion and inflammatory reaction. Biopsies of oral squamous cell carcinomas were deparaffinised, processed for antigen unmasking procedures and stained with antibody antiLaminin-5 $\gamma 2$. By light microscopy, 4 optical fields of x200 were selected in three different areas including normal, dysplastic and invading epithelia. Positive cells were counted and divided into three categories, which included $<20$ cells, between 21 and 50 cells and $>50$ stained cells. Patient survival was analyzed by Kaplan-Mayer curves. $\gamma 2$-positive cells were found in the basal layer of dysplastic epithelium, within inflammatory infiltrate, at the margins of differentiated invading islands and at the forefront of undifferentiated invading nests. Observations showed that an increased number of $\gamma 2$-positive cells correlated significantly with a shorter life expectancy under invading epithelia (log-rank test $\mathrm{p}<0.05$ ), not when a count was performed under normal or dysplastic epithelia of the same patient. The number of $\gamma 2$ positive cells also correlated with the histopathological pattern
\end{abstract}

Correspondence to: Dr Alberto Gasparoni, Dipartimento di Farmacologia 'G. Segre' - Sezione di Anatomia, Università degli Studi di Siena, Strada delle Scotte 6, 53100 Siena, Italy

E-mail: albertogasparoni@yahoo.com

Key words: laminin-5 $\gamma 2$, oral squamous cell carcinomas, patients' survival, immunohistochemistry, basement membrane of invasion. Our results show that $\gamma 2$ may be a reliable prognostic tool for oral squamous cell carcinomas.

\section{Introduction}

Among the components of basement membrane, Laminins have been the focus of many studies for their involvement in initial steps in tissue invasion in oral cancer (1-6). These molecules have been shown to be involved not only in genetic diseases, but also to regulate the migratory (7) and proliferative (8) capabilities of keratinocytes in vitro and in vivo.

Laminin-5, previously called Nicein, Kalinin, Epiligrin, Ladsin, is one of the isomers widely studied and is found in the basement membrane of stratified normal epithelia as a trimeric form composed by subunits $\alpha 3, \beta 3$, and $\gamma 2$, controlled by three genes LAMA3, LAMB3 and LAMC2 (8). Laminin-5 provides mostly an adhesive function, by binding the extracytoplasmic moiety $\alpha_{6}$ of integrin $\alpha_{6} \beta_{4}$ in skin hemidesmosomes and $\alpha_{3} \beta_{1}$ in cultured cells to the basement membrane (9) and also by activating the Grb2/RAS signalling pathway during migration events (10). Although several sites of the molecule are known to participate in cellular-extracellular matrix interactions, Laminin-5 seems to be associated with epithelial tissue adhesion, whereas the short arm of its subunit $\gamma 2$ has been shown to be able to facilitate cell migration in normal cells during wound healing $(11,12)$ and in tumor cells during tissue invasion (13). This capability is maintained also after Laminin-5 cleavage by tissue metalloproteases, resulting in the release of the subunit $\gamma 2$ (9). As $\gamma 2$-positive cells are present at the margins of invading epithelia in oral squamous cell carcinomas and they correlate with a shorter life expectancy (14), expression of the epidermal growth factor receptor $(15,16)$, and advancement of cancerous cells (17), it has been hypothesized that the expression of the short arm could be an indicator of malignancy and at the same time a target for cancer-related gene therapy.

Trying to determine a better relationship between the subunit $\gamma 2$ of Laminin-5 and its value as a prognostic indicator 
of cancer malignancy, we analyzed quantitatively and qualitatively a library of 65 oral squamous cell carcinomas for expression of $\gamma 2$ subunit and correlated its expression with several histopathological and clinical parameters, including TNM stage, peritumoral inflammation, size of the lesion, and patient survival. Our primary goal was to assess whether the number of $\gamma 2$-positive cells detected under normal, dysplastic and cancerous tissues would correlate with survival. Other hypotheses tested included correlation between histopathological and TNM staging, inflammation, size and the number of $\gamma 2$ expressing cells.

\section{Materials and methods}

Oral squamous cell carcinoma samples and immunohistochemistry. In the present study, a library of 65 formalinfixed, paraffin-embedded biopsies, collected at the Department of Human Pathology, University of Marche, Italy, from 1990 to 2003 previously diagnosed as oral squamous cell carcinomas were used. Consent was obtained to use clinical and histopahological data from all patients for research and teaching purposes. Sections (3-5 $\mu$ ) were cut from specimens, placed on slides (Fisher Superfrost Plus, Fisher Diagnostics, Middletown, VA, USA), deparaffinised, rehydrated and endogenous peroxidase blocked by incubation in $0.3 \%$ hydrogen-peroxide $50 \%$ methanol. After blocking, slides were boiled for $40 \mathrm{~min}$ at $95^{\circ} \mathrm{C}$ in antigen unmasking solution DakoCytomation Target Retrieval Solution (pH 9.0, Dako, Denmark). After cooling, slides were washed in phosphate buffer saline (PBS) solution and non-specific sites blocked by incubating slides for $15 \mathrm{~min}$ at room temperature in a $5 \%$ solution of bovine serum albumin (BSA) in PBS (BSA/PBS). On a limited number of slides, a more aggressive treatment for antigen unmasking was done by incubation in Protease XXIV (Sigma Scientific, St. Louis, MO) for $30 \mathrm{~min}$ at $40^{\circ} \mathrm{C}$ to evidence the basement membrane. Slides were then incubated with a mixture of primary monoclonal mouse antibody against amino acids 382-608 of human Laminin-5 $\gamma 2$ (diluted 1:20, Chemicon International, Temecula, CA) in 5\% BSA/PBS for $60 \mathrm{~min}$, washed three times in PBS, then incubated with 1:200 of a mixture of secondary antibody anti-mouse IgG conjugated with peroxidase (Sigma). After washing, immunoreactions were developed by incubating sections with peroxidise substrate Sigma Fast ${ }^{\mathrm{TM}}$ 3,3'Diaminobenzidine (DAB, Sigma) dissolved in $1 \mathrm{ml}$ of deionised water. Reactions were monitored and stopped by gentle washing in water and then slides were covered with a coverslip and observed by conventional light microscopy. Ten specimens of normal gingival and alveolar mucosal tissue were used for detection of Laminin-5 $\gamma 2$ in normal tissue. Negative controls were run by omitting primary antibody. Histopathological and clinical data were collected for each patient (Table I). Histopathological data, including tumor stage, inflammatory infiltrate and TNM grading (Table I, columns $\mathrm{J}, \mathrm{K}$, and $\mathrm{L}$, respectively) were assessed on hematoxylin-eosin stained slides by two pathologists (L.L.M. and C.R.). Clinical parameters including anatomical location in the oral cavity, patient survival, and size of the lesion at diagnosis (Table I) were obtained from the database of the Department of Pathology.
Counts of $\gamma 2$-positive cells. In each specimen, areas of apparently normal epithelium, dysplastic epithelium with an apparent intact basement membrane and invasive epithelium were selected and 4 optical fields of x 200 observed beginning from the basement membrane toward the deeper tissue, including the lamina propria and underlying tissue. Specimens where epithelium was not distinguishable were not included. Positive cells were counted in every field and their total count was used for significant differences. Numbers of $\gamma 2$-positive cells were divided into three groups, according to the number of positive cells detected under normal, dysplastic, and invasive epithelia (Table II). The first group included counts up to 20-positive cells within all the 4 fields. The second group included the number of positive cells between 21 and 50 . The third group included the number of positive cells with $>50$ stained cells.

TNM grading, size, staging, inflammation and histopathological analyses. The relationship between the count of $\gamma 2$-positive cells and tumor parameters was done according to the following procedures. According to the size of the original lesion, tumors were divided into 5 categories: group 1 included lesions up to $1 \mathrm{~cm}$ in diameter; group 2 between 1.01 and $2 \mathrm{~cm}$; group 3 between 2.01 and $3 \mathrm{~cm}$; group 4 between 3.01 and $4 \mathrm{~cm}$, group 5 included lesions with a diameter $>4.01 \mathrm{~cm}$. Inflammation was assessed subjectively with scores of 1 , with little inflammatory infiltrate, 2 evident inflammatory infiltrate, and 3 with a thick band of infiltrate occupying most of the lamina propria. The relationship between the histopathological differentiation of the tumor and the $\gamma 2$ staining pattern was evaluated by applying a combined score, which would consider both pattern of tissue invasion $(18,19)$ and percentage of $\gamma 2$-positive cells, by giving a score of 1 if the tumor showed round, differentiated invasive islands, with $<10 \%$ cells stained; a score of 2 was given if the tumor showed a pattern of invasion with round, differentiated islands, with $>10 \% \quad \gamma 2$-positive cells stained at the margins; a score of 3 was given if non- differentiated nests, with $<10 \% \quad \gamma 2$-positive cells stained per optical field were observed at the invasive front of the tumor; a score of 4 was given if non differentiated nests or isolated cells, with $>10 \% \gamma 2$-positive cells stained were observed at the invasive front of the tumor; a score of 5 was given if $>50 \%$ of the invasive cells appeared positive at the invading front. After calibration to define patterns of staining and appropriate quantitative analysis, evaluations were made by an observer (A.G.), blind as to the section and clinical data. Doubts as to the interpretation of staining and classification of the slides were resolved by consultation with pathologists (L.L.M. and C.R.).

Statistical analysis. The survival was analyzed by KaplanMayer curves. Significant differences among the three groups of $\gamma 2$-positive cells (i.e., cells under normal, dysplastic, and cancerous epithelia) were tested by the log-rank test. Correlations between variables were tested by Spearman's rank correlation rho, Kendall's rank correlation tau, and Pearsons' Chi-squared test. Significance was accepted at $p<0.05$ in all analyses. The analyses were performed using the programme $\mathrm{R}$ and the package Design $(20,21)$. 
Table I. Histopathological and clinical characteristics for the specimens analyzed.

No. Location Normal Dysplasia Cancer Histopathol. Months Size $\begin{gathered}\text { Grouped Inflammatory TNM } \\ \text { size Stage }\end{gathered}$ score

\begin{tabular}{|c|c|c|c|c|c|c|c|c|c|c|}
\hline 1 & Lower lip & 0 & 0 & 0 & 3 & 28 & 0.70 & 1.00 & 1 & T1N0 \\
\hline 2 & Lower lip & 0 & 1 & 2 & 5 & 28 & 1.50 & 2.00 & 2 & T1N0 \\
\hline 3 & Tongue & 0 & 0 & 1 & 4 & 29 & 1.50 & 2.00 & 2 & T1N1 \\
\hline 4 & Tongue & 0 & 0 & 1 & 4 & 27 & 0.90 & 1.00 & 2 & T1N0 \\
\hline 5 & Tongue & 0 & 0 & 1 & 4 & 28 & 3.00 & 3.00 & ND & T1N2B \\
\hline 6 & Gingiva & 0 & 0 & 0 & 3 & 25 & 0.80 & 1.00 & 2 & T1N0 \\
\hline 7 & Cheek & 0 & 0 & 1 & 4 & 28 & 0.80 & 1.00 & 2 & T1N0 \\
\hline 8 & Lower lip & 0 & 0 & 0 & 0 & ND & 0.70 & 1.00 & 1 & T1N0 \\
\hline 9 & Tongue & 1 & 1 & 1 & 2 & 8 & 1.20 & 2.00 & 2 & T1N0 \\
\hline 10 & Gingiva & 0 & 0 & 1 & 4 & 1 & 4.00 & 4.00 & 0 & T4AN0 \\
\hline 11 & Cheek & 1 & 0 & 1 & 2 & 120 & 1.50 & 2.00 & 2 & T1N0M0 \\
\hline 12 & Tongue & 2 & 0 & 1 & 1 & 120 & 3.50 & 4.00 & 1 & T2NO \\
\hline 13 & Gingiva & 0 & 1 & 1 & 4 & 81 & 1.20 & 2.00 & 3 & T1N0 \\
\hline 14 & Tongue & 0 & 0 & 0 & 3 & 156 & 3.00 & 3.00 & 2 & $\mathrm{~T} 2 \mathrm{~N} 2 \mathrm{~B}$ \\
\hline 15 & Tongue & 2 & 1 & 0 & 2 & ND & 3.00 & 3.00 & 1 & T4AN0 \\
\hline 16 & Cheek & 0 & 1 & 0 & 1 & 88 & 3.50 & 4.00 & 1 & T2N0 \\
\hline 17 & Tongue & 1 & 1 & 0 & 2 & 130 & 1.00 & 1.00 & 2 & TN1 \\
\hline 18 & Tongue & 1 & 1 & 0 & 2 & 130 & 1.00 & 1.00 & ND & T1N0 \\
\hline 19 & Cheek & 0 & 0 & 1 & 1 & 104 & 2.50 & 3.00 & 1 & T2N0 \\
\hline 20 & Lower lip & 2 & 0 & 0 & 3 & 156 & 1.00 & 1.00 & 2 & T1N0 \\
\hline 21 & Tongue & 0 & 0 & 0 & 2 & 48 & 1.50 & 2.00 & 3 & T1N0 \\
\hline 22 & Gingiva & 0 & 0 & 0 & 1 & 62 & 3.50 & 4.00 & 2 & T4AN0 \\
\hline 23 & Tongue & 0 & 0 & 0 & 3 & 17 & 2.00 & 2.00 & 3 & T1N0 \\
\hline 24 & Cheek & 1 & 0 & 1 & 2 & 27 & ND & ND & 1 & T1N0 \\
\hline 25 & Tongue & 0 & 0 & 0 & 3 & 25 & 1.00 & 1.00 & 1 & T1N0 \\
\hline 26 & Cheek & 0 & 0 & 0 & 4 & 27 & 1.00 & 1.00 & 1 & T1N0 \\
\hline 27 & Floor & 0 & 0 & 1 & 3 & 45 & ND & ND & 1 & TN2B \\
\hline 28 & Cheek & 0 & 0 & 1 & 1 & 29 & 1.00 & 1.00 & 3 & T1N0 \\
\hline 29 & $\begin{array}{l}\text { Tongue } \\
\text { lingual }\end{array}$ & 0 & 0 & 0 & 4 & 8 & 1.00 & 1.00 & 1 & T1N2A \\
\hline 30 & Fornix & 2 & 0 & 1 & 4 & 78 & 2.30 & 3.00 & 2 & T4AN0 \\
\hline 31 & Tongue & 2 & 0 & 2 & 3 & 34 & 3.00 & 3.00 & 2 & $\mathrm{~T} 2 \mathrm{~N} 2 \mathrm{~B}$ \\
\hline 32 & Cheek & 2 & 0 & 2 & 4 & 97 & 1.00 & 1.00 & 1 & T1N2B \\
\hline 33 & Tongue & 0 & 0 & 2 & 5 & 11 & 3.20 & 4.00 & 1 & $\mathrm{~T} 2 \mathrm{~N} 2 \mathrm{~B}$ \\
\hline 34 & Gingiva & 2 & 1 & 2 & 5 & 102 & 3.00 & 3.00 & 2 & $\mathrm{~T} 2 \mathrm{~N} 1$ \\
\hline 35 & Tongue & 0 & 0 & 2 & 5 & 120 & 1.50 & 2.00 & 1 & T1N0 \\
\hline 36 & Gingiva & 0 & 0 & 0 & 2 & 54 & 3.50 & 4.00 & 1 & T4AN0 \\
\hline 37 & Cheek & 2 & 0 & 0 & 5 & 120 & 1.80 & 2.00 & 3 & T1N0 \\
\hline 38 & Tongue & 2 & 0 & 0 & 1 & 36 & 1.50 & 2.00 & 1 & T1N0 \\
\hline 39 & Lower lip & 2 & 0 & 0 & 3 & 120 & 1.00 & 1.00 & ND & T1N0 \\
\hline 40 & Cheek & 2 & 0 & 0 & 3 & 88 & 1.00 & 1.00 & 0 & TN2B \\
\hline 41 & Cheek & 0 & 0 & 0 & 1 & 10 & 1.00 & 1.00 & 1 & TN2B \\
\hline 42 & Cheek & 0 & 0 & 0 & 2 & 25 & 2.00 & 2.00 & 1 & T4AN0 \\
\hline 43 & Gingiva & 0 & 0 & 1 & 2 & 17 & 1.50 & 2.00 & 1 & T1N2B \\
\hline 44 & Tongue & 0 & 0 & 0 & 2 & 3 & 5.00 & 5.00 & 1 & T4AN0 \\
\hline 45 & Floor & 0 & 0 & 1 & 4 & 14 & 3.00 & 3.00 & 1 & $\mathrm{~T} 2 \mathrm{~N} 1$ \\
\hline 46 & Floor & 2 & 0 & 0 & 3 & 16 & 2.00 & 2.00 & 2 & T2NO \\
\hline 47 & Cheek & 1 & 0 & 0 & 4 & 24 & 5.50 & 5.00 & 1 & T3N0 \\
\hline 48 & Cheek & 0 & 0 & 0 & 3 & 6 & 0.70 & 1.00 & 2 & T1N0 \\
\hline 49 & Cheek & 0 & 0 & 0 & 3 & 19 & 2.20 & 3.00 & 2 & T2N0 \\
\hline 50 & Tongue & 1 & 0 & 0 & 2 & 106 & 1.00 & 1.00 & 1 & T1N0 \\
\hline 51 & Tongue & 2 & 1 & 0 & 2 & 54 & 2.50 & 3.00 & 2 & T2NO \\
\hline 52 & Cheek & 2 & 0 & 0 & 3 & 79 & 4.00 & 4.00 & 2 & T2N0 \\
\hline 53 & Tongue & 1 & 0 & 0 & 3 & 6 & 3.50 & 4.00 & 1 & T2NO \\
\hline 54 & Cheek & 0 & 0 & 0 & 3 & 77 & 5.00 & 5.00 & 2 & T4AN0 \\
\hline
\end{tabular}


Table I. Continued.

\begin{tabular}{|c|c|c|c|c|c|c|c|c|c|c|c|}
\hline No. & Location & Normal & Dysplasia & Cancer & $\begin{array}{l}\text { Histopathol. } \\
\text { combined } \\
\text { score }\end{array}$ & Months & Size & $\begin{array}{l}\text { Grouped } \\
\text { size }\end{array}$ & $\begin{array}{c}\text { Inflammatory } \\
\text { infiltrate }\end{array}$ & TNM & Stage \\
\hline 55 & Cheek & 1 & 0 & 1 & 1 & 72 & 2.20 & 3.00 & 1 & T2NO & 2 \\
\hline 56 & Cheek & 0 & 0 & 0 & 3 & 89 & 1.70 & 2.00 & 1 & T4ANO & 4 \\
\hline 57 & Gingiva & 1 & 1 & 0 & 1 & ND & 1.00 & 1.00 & ND & T1N0 & 1 \\
\hline 58 & Cheek & 0 & 0 & 0 & 3 & 6 & 4.00 & 4.00 & 2 & T2NO & 2 \\
\hline 59 & Floor & 0 & 0 & 0 & 3 & 40 & 3.70 & 4.00 & 1 & T4AN0 & 4 \\
\hline 60 & Floor & 2 & 0 & 1 & 2 & 44 & 2.00 & 2.00 & 1 & T1N2B & 4 \\
\hline 61 & Tongue & 0 & 1 & 1 & 4 & 52 & 2.50 & 3.00 & 1 & T2NOMO & 2 \\
\hline 62 & Gingiva & 0 & 0 & 1 & 4 & 40 & 6.00 & 5.00 & 1 & T4AN2B & 4 \\
\hline 63 & Cheek & 2 & 0 & 0 & 2 & 13 & 2.40 & 3.00 & 1 & T2N2B & 4 \\
\hline 64 & Cheek & 0 & 0 & 1 & 4 & 47 & 2.80 & 3.00 & 3 & T2NO & 2 \\
\hline 65 & Gingiva & 2 & 0 & 1 & 2 & 2 & 1.00 & 1.00 & 1 & T4AN2B & 4 \\
\hline
\end{tabular}

$\mathrm{ND}$, not determined.

Table II. Summary table showing the frequency of each count for $\gamma 2$-positive cells within normal, dysplastic, and invasive epithelium and the average survival rate (in months) for each group.

\begin{tabular}{lcccc}
\hline $\begin{array}{l}\text { Counts of } \gamma 2- \\
\text { positive cells }\end{array}$ & $\begin{array}{c}\text { Frequency under } \\
\text { normal epithelium }\end{array}$ & $\begin{array}{c}\text { Frequency under } \\
\text { dysplastic epithelium }\end{array}$ & $\begin{array}{c}\text { Frequency under } \\
\text { invasive epithelium }\end{array}$ & $\begin{array}{c}\text { Mean survival } \\
\text { rate (months) }\end{array}$ \\
\hline $0-20$ & 62 & 55 & 37 & $67.45 \pm 45.6$ \\
$21-50$ & 3 & 11 & 22 & $39.4 \pm 33.8$ \\
$>50$ & 1 & 0 & 6 & $17.8 \pm 7.75$ \\
\hline
\end{tabular}
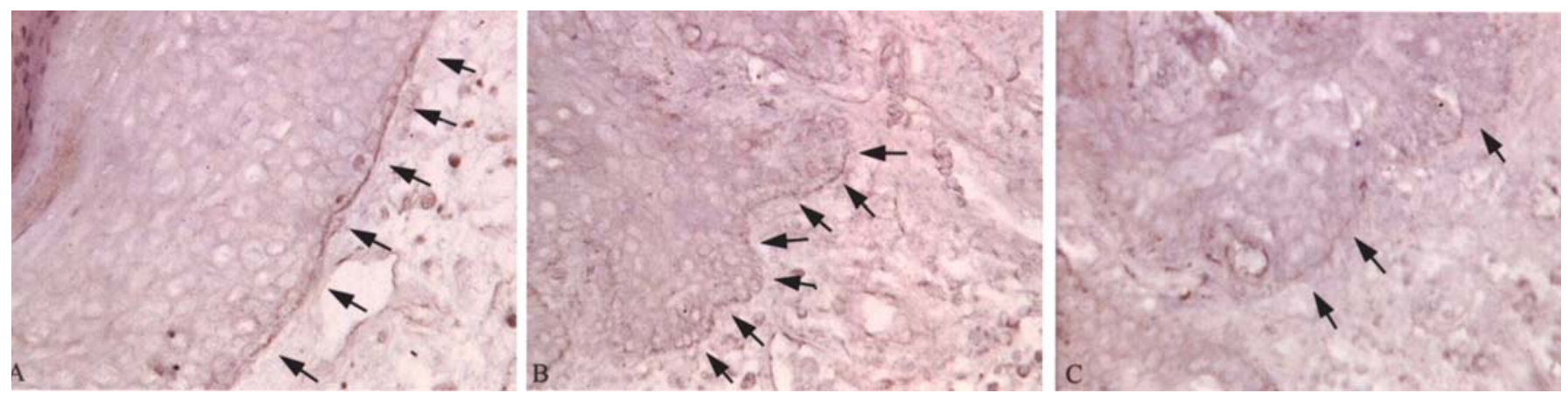

Figure 1. Staining of the basement membrane with antibody against Laminin-5 $\gamma^{2}$ in normal (A), dysplastic (B), and invasive epithelia (C). Staining is present in A and B, but not detectable in C. Light microscopy $\mathrm{x} 400$.

\section{Results}

Immunolocalization of Laminin-5 $\gamma 2$ in oral squamous cell carcinomas. Of the 65 specimens, 5 were biopsies of lesions of the lips; 10 of keratinized gingiva; 22 of the tongue; 22 of the cheek mucosa; 5 of the floor of the mouth and 1 of the lingual fornix. Negative controls showed no positive staining throughout the epithelium or connective tissue. In all our samples, no staining with the antibody anti Laminin-5 $\gamma 2$ was detectable at the level of the basement membrane of normal or dysplastic tissue, with the exception of biopsies treated with extensive protease digestion, where positive membrane staining was evident in areas of squamous stratified epithelial tissue with a normal appearance (Fig. 1A). Staining in the same biopsy decreased in areas of dysplastic epithelium (Fig. 1B), and disappeared in areas of breakage of the basement membrane (Fig. 1C). In less aggressive conditions of antigen unmasking, $\gamma 2$ staining was rarely present in isolated cells of the basal layer of normal and dysplastic epithelium and underlying connective tissue (Fig. 2A-D). In areas of dysplastic tissue and where integrity of the basement membrane was not conserved, three patterns of staining were observed. The first 


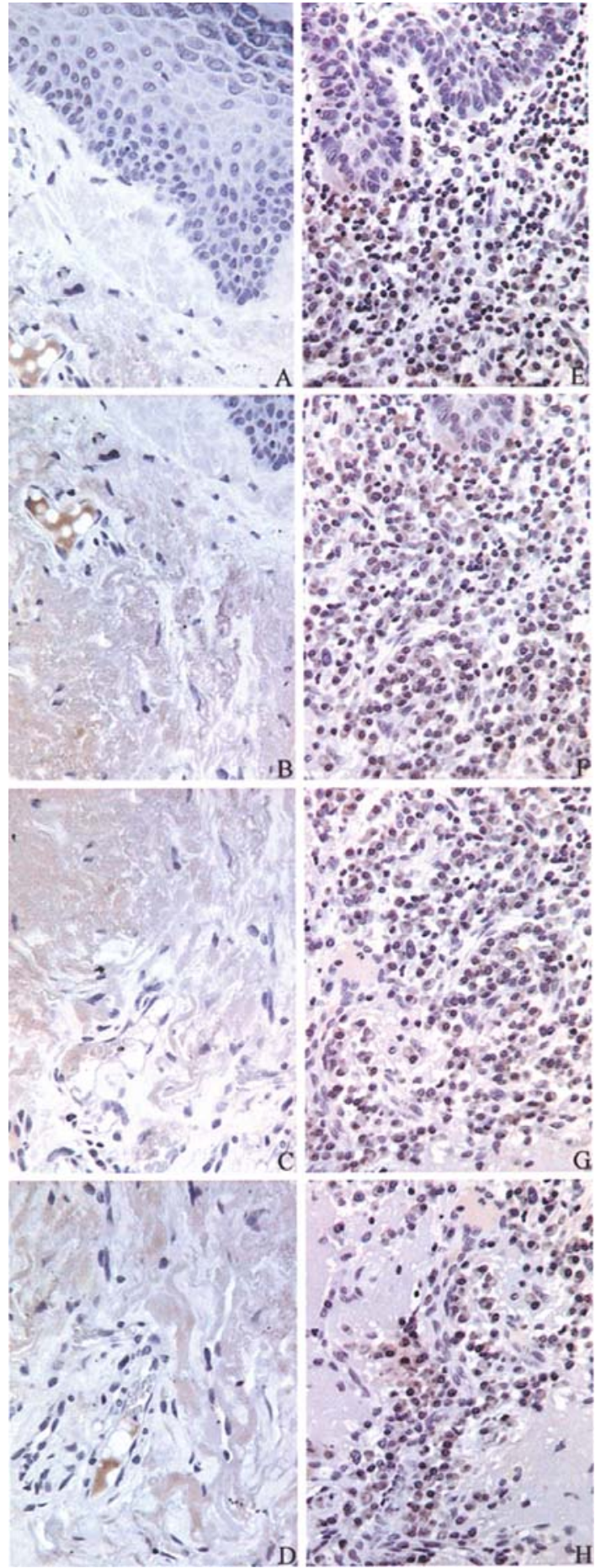

Figure 2. Positive $\gamma 2$ cells under normal appearing epithelium (A-D) and invasive epithelium $(\mathrm{E}-\mathrm{H})$ of the same specimen. Large number of positive $\gamma 2$ cells are present within the inflammatory infiltrate underlying epithelium (E-F) and deeper in the connective tissue (G-H). Light microscopy x200.

pattern included $\gamma 2$-positive cells within areas of strong inflammatory and immune reaction in the lamina propria (Fig. 2F-H), under dysplastic epithelium without apparent breakage of the basement membrane and invasive epithelium. The second pattern showed cells positively stained at the margins of invading compact islands (Fig. 3A-B) within the connective tissue. These $\gamma 2$-positive cells were sparsely distributed throughout the whole periphery. The third pattern

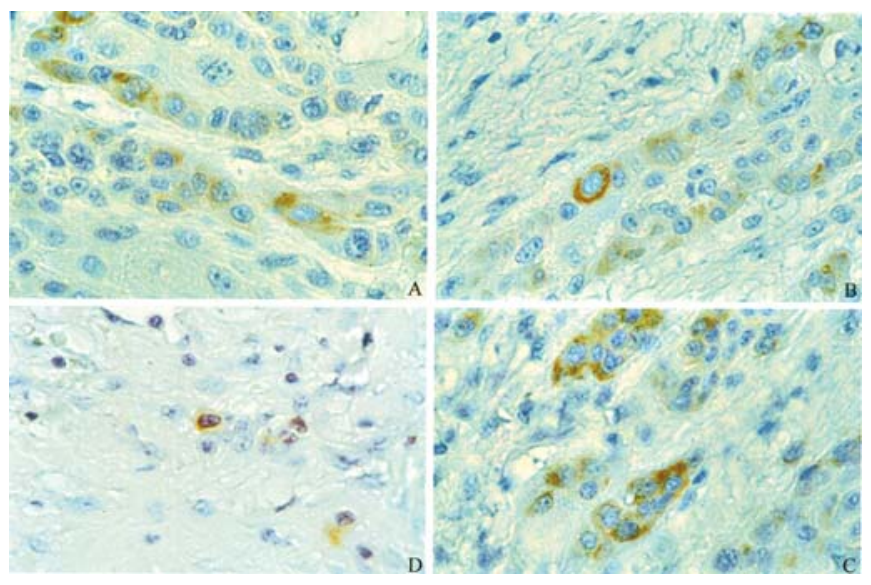

Figure 3. Positive $\gamma 2$ cells at the margins of invading islands (A, B), at the invasive front $(C)$, or isolated within the connective tissue (D). Light microscopy, A-B x630; C-D x400.

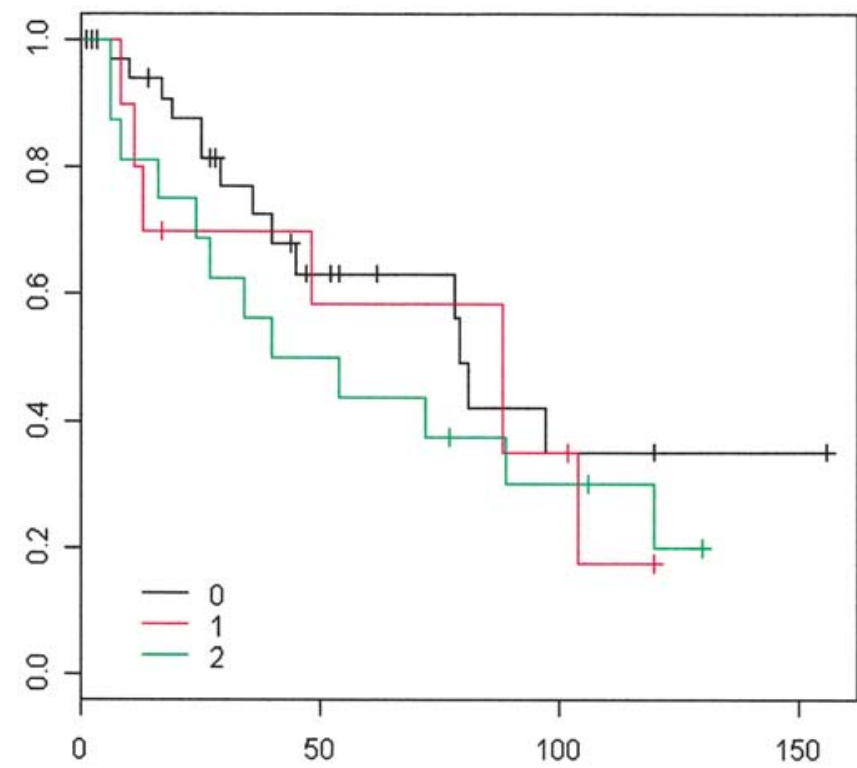

Figure 4. Kaplan Mayer curves relative to patient survival and number of $\gamma 2$-positive cells under normal epithelium. No correlation is present between the number of positive cells and survival $(\mathrm{p}>0.05)$. Line 0 : survival curve in patients with counts of $\gamma 2$-positive cells $<20$ in 4 optical fields; line 1 : survival curve in patients with counts of $\gamma 2$-positive cells between 21 and 50; line 2: survival curve in patients with counts of $\gamma 2$-positive cells $>50$.

involved groups of positive cells at the invasive front of invading epithelium or isolated cells in the connective tissue (Fig. 3C and D).

Correlation with patient survival, lesion size, tumor staging, and inflammatory infiltrate. As some positive cells were observable within the normal tissue, we counted positive cells under normal appearing epithelial tissue. When counted under normal-appearing (Fig. 4) or dysplastic (Fig. 5) epithelial tissues without clear signs of invasion, the number of $\gamma 2$ positive cells did not correlate with the survival curves $(\mathrm{P}=0.47$ and $\mathrm{P}=0.66$, respectively). Under normal-appearing tissue, the total number of $\gamma 2$-positive cells were usually below 


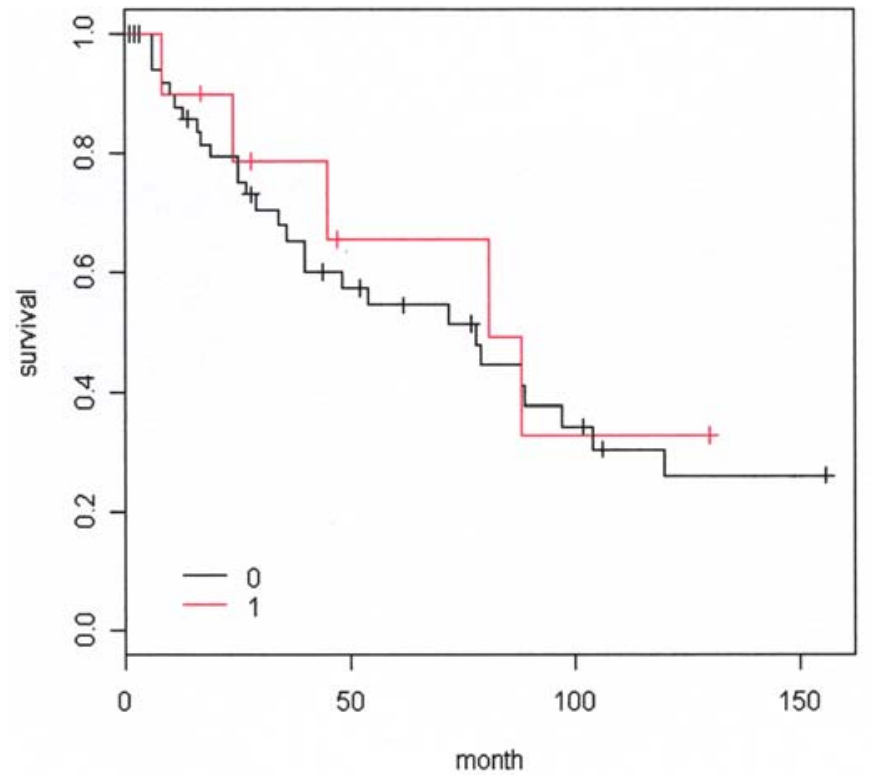

Figure 5. Kaplan Mayer curves relative to patient survival and number of $\gamma 2$-positive cells under dysplastic epithelium. No correlation is present between the number of positive cells and survival $(p>0.05)$. Lines refer to the same groups as in Fig. 4.

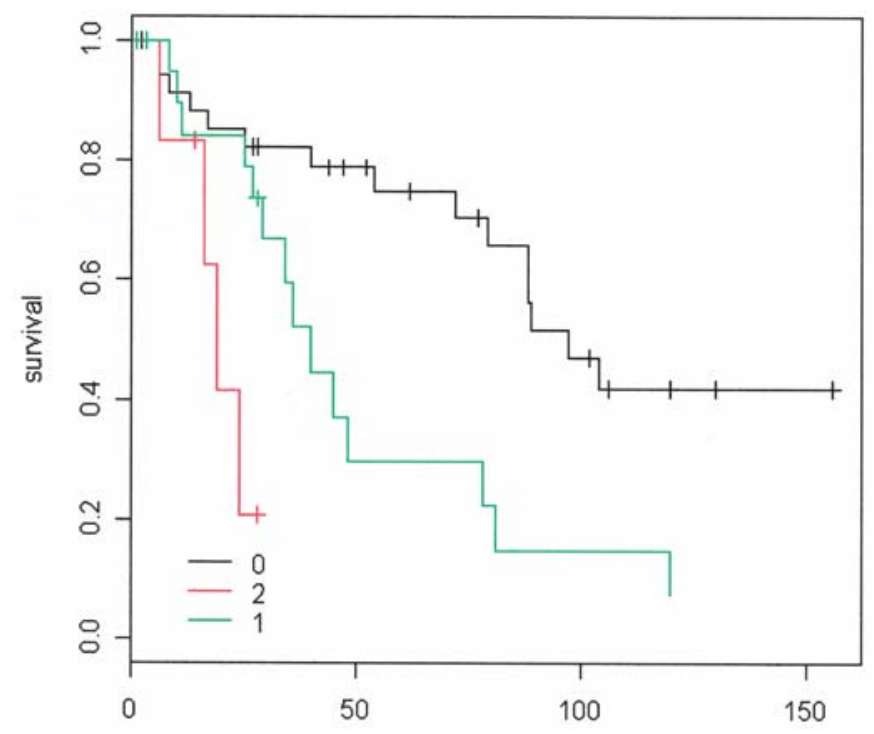

Figure 6. Kaplan Mayer curves relative to patient survival and number of $\gamma 2$-positive cells under invasive epithelium. The largest number of positive cells significantly correlates with a shorter survival period $(p<0.05)$. Lines refer to the same groups as in Fig. 4.

10 in the four optical fields $(n=62) ; 3$ cases showed $\gamma 2$-positive cells between 11 and 30 cells, one case showed $>30 \gamma 2$-positive cells, with one case lost. Under dysplastic epithelia with no evident breakage of the basement membrane, 55 cases showed $<10 \gamma 2$-positive cells, 11 cases showed a count of $\gamma 2$-positive cells between 11 and 30 , and no case showed >50 cells. Number of $\gamma 2$-positive cells in invasive epithelia correlated significantly with the survival curves (Fig. 6, $\mathrm{P}=0.004$ ). Of all the specimens examined, $37 \mathrm{had}<10 \gamma 2$-positive cells in the 4 optical fields, 22 had between 21 and $50 \gamma 2$-positive

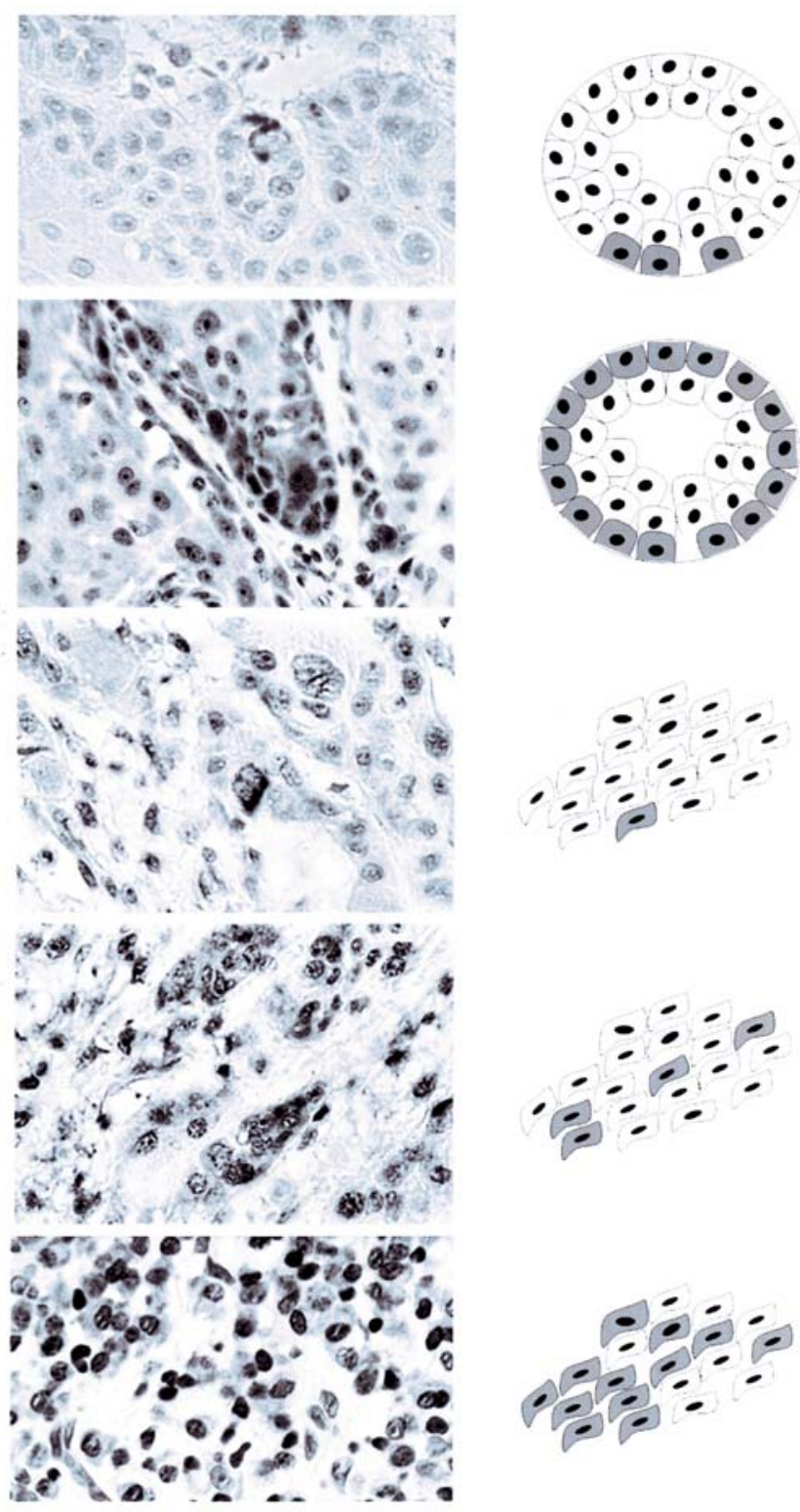

Figure 7. Pattern of invasion and percentage of $\gamma 2$-positive cells. First row: microscopic slide (left) and scheme (right) of compact invading islands, with $<10 \%$ positive cells; second row: compact invading islands with $>10 \%$ positive cells; third row: invading cells with $<10 \%$ cells stained; fourth row: invading cells with $>10 \%$ stained cells; fifth row: $>50 \%$ cells stained.

cells, 6 had $>50$ cells (Table II). The average survival rate was $67.45 \pm 45.6$ months for the group with $<10 \gamma 2$-positive cells detectable, with two cases lost. The average survival rate was $39.4 \pm 33.8$ months for the group with $11-40$ cells detectable in the four optical fields, with one case lost and the average survival was $17.8 \pm 7.75$ months for the group with total number of $\gamma 2$-positive cells $>50$ cells. No significant correlation was found between number of $\gamma 2$ positive cells and tumor stage (Kendall's rank correlation tau, $\mathrm{P}=0.36)$, inflammatory infiltrate $(\mathrm{P}=1.38)$, size of the lesion $(\mathrm{p}=0.49)$, or TNM grouping $(\mathrm{P}=0.81)$. Significant correlation was found between the modified histopathological combined score (Fig. 7) and patient survival (Fig. 8). 


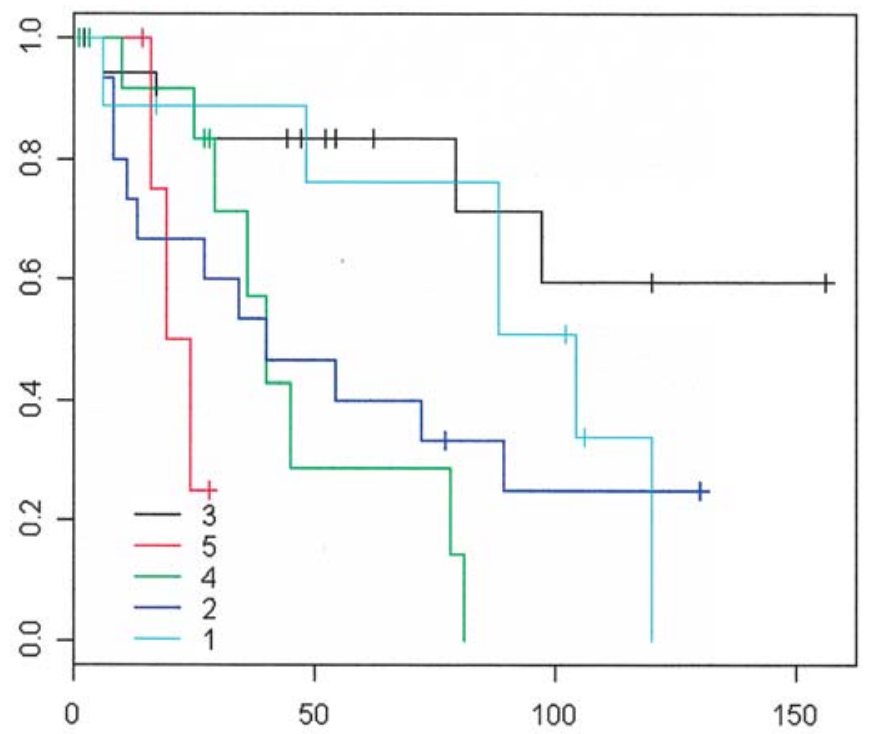

Figure 8. Prognostic value of combined $\gamma 2$ positive cell numbers and pattern of invasion. Specimens grouped in line 1 showed round, well differentiated invasive islands, with less than $10 \%$ of cells stained; line 2 presented a pattern of invasion similar to the previous one, with round, differentiated invasive islands, but $>10 \%$ of cells stained; line 3 and 4 , specimens were characterized by non-differentiated invasive nests, with $<10 \%$ (line 3 ) and $>10 \%$ cells stained (line 4), respectively; line 5, undifferentiated invasive cells, of whom $>50 \%$ reacted positively to the antibody anti-laminin $5 \gamma 2$.

\section{Discussion}

Several studies have suggested that the Laminin-5 $\gamma 2$ signalling pathway may be relevant in tissue invasion in malignant cells of the oral cavity and should therefore be considered as a marker of malignancy $(14,22,23)$. In our study, the primary goal was to determine, by immunohistochemistry, if the number of Laminin-5 $\gamma 2$-positive cells could be a reliable marker of tumor malignancy. To determine if this was a characteristic of invasive tissue, we counted $\gamma 2$-positive cells in three parts of the biopsies, which showed an apparent normal epithelium, dysplastic epithelium with no breakage of basement membrane, and invasive epithelium. With the antibody used, specific for Laminin-5 $\gamma 2$, we could not detect any basement membrane staining in normal or invasive tissue, unless a more aggressive unmasking treatment was used. This suggests that the antibody reacts with an epitope hidden in the basement membrane and is exposed by prolonged trypsin digestion. This hypothesis is consistent with the shape and integrity of the heterotrimeric Laminin-5 molecule in the basement membrane.

Positive $\gamma 2$ cells were rarely observed in basal layer of oral epithelia, more often among inflammatory infiltrate in lamina propria and invading nests within the connective tissue. Statistically, the largest number of $\gamma 2$-positive cells showed a significant correlation with patient survival, confirming data reported by Ono et al (14). In addition, we have shown that the number of $\gamma 2$ expressing cells is a characteristic of invasive epithelia, as counts are significantly higher than in normal and dysplastic tissue of the same section. Thus, our study confirms the prognostic role that a high number of $\gamma 2$ positive cells within the invading nests and cells of oral squamous cell carcinomas may have. In addition, a significant correlation with survival was found also using a score, which considers the pattern of invasion and $\gamma 2$ cells, similarly to the system used by Ono et al (14). Thus, the pattern of invasion and $\gamma 2$ cells may represent an improved prognostic tool.

In the present study, we failed to show a correlation with other tumor histopathological parameters. The lack of correlation with inflammatory infiltrate suggests $\gamma 2$-positive cells should not be associated with inflammatory infiltrate. However, the lack of correlation with tumor stage and TNM classification was unexpected. Statistical analyses with several groupings of TNM classification failed to show any association. This result is in contrast with that reported by Ono et al (14). The reasons of this discrepancy may be related to the different specimens we used (samples from multiple sites in the oral cavity), versus the specimens used by Ono et al (samples of tongue carcinomas), or the specific samples with lymph node metastasis included (14). Interestingly, by applying a modified score, which considered both the pattern of invasion and the presence of $\gamma 2$-positive cells, we observed a significant correlation with patient survival.

Therefore, we conclude that large numbers of Laminin-5 $\gamma 2$ cells should be considered as a negative prognostic factor of malignancy in oral squamous cell carcinomas. It is likely that a score involving both the number of $\gamma 2$-positive cells and histological pattern of invasion may constitute a reliable tool for identifying more aggressive tumors of the oral cavity.

\section{References}

1. Thorup AK, Reibel J, Schiodt M, Stenersen TC, Therkildsen MH, Carter WG and Dabelsteen E: Can alterations in integrin and Laminin-5 expression be used as markers of malignancy? APMIS 106: 1170-1180, 1998.

2. Kosmehl H, Berndt A, Strassburger S, et al: Distribution of Laminin and fibronectin isoforms in oral mucosa and oral squamous cell carcinoma. Br J Cancer 81: 1071-1079, 1999.

3. Haas KM, Berndt A, Stille KJ, Hyckel P and Kosmehl H: A comparative quantitative analysis of Laminin-5 in the basement membrane of normal, hyperplastic and malignant oral mucosa by confocal immunofluorescence imaging. J Histochem Cytochem 49: 1261-1268, 2001.

4. Yuen HW, Ziober AF, Gopal P, et al: Suppression of Laminin-5 expression leads to increased motility, tumorigenicity, and invasion. Exp Cell Res 309: 198-210, 2005.

5. Kawano K and Yanagisawa S: Predictive value of Laminin-5 and membrane type 1-matrix metalloproteinase expression for cervical lymph node metastasis in T1 and $\mathrm{T} 2$ squamous cell carcinomas of the tongue and floor of the mouth. Head Neck 28: 525-533, 2006.

6. Koshikawa N, Giannelli G, Cirulli V, Miyazaki K and Quaranta V: Role of cell surface metalloprotease MT1-MMP in epithelial cell migration over Laminin-5. J Cell Biol 148: 615-624, 2000 .

7. Natarajan E, Omobono JD. $2^{\text {nd }}$, Jones JC and Rheinwald JG: Co-expression of p16INK4A and Laminin-5 by keratinocytes: a wound-healing response coupling hypermotility with growth arrest that goes awry during epithelial neoplastic progression. J Investig Dermatol Symp Proc 10: 72-85, 2005.

8. Katayama M and Sekiguchi K: Laminin-5 in epithelial tumor invasion. J Mol Histol 35: 277-286, 2004.

9. Mareel $\mathrm{M}$ and Leroy A: Clinical, cellular and molecular aspects of cancer invasion. Physiol Rev 83: 337-376, 2003.

10. Giancotti FG: Signal transduction by the $\alpha_{6} \beta_{4}$ integrin: charting the path between Laminin binding and nuclear events. J Cell Sci 109: 1165-1172, 1996.

11. Salo S, Haakana H, Kontusari S, Hujanen E, Kallunki T and Tryggvason K: Laminin-5 promotes adhesion and migration of epithelial cells: identification of a migration-related element in the g2 chain gene (LAMC2) with activity in transgenic mice. Matrix Biol 18: 197-210, 1999. 
12. Natarajan E, Saeb M, Crum CP, Woo SB, McKee PH and Rheinwald JG: Coexpression of p16 (INK4A) and Laminin-5 $\gamma^{2}$ by microinvasive and superficial squamous cell carcinomas in vivo and by migrating wound and senescent keratinocytes in culture. Am J Pathol 163: 477-491, 2003.

13. Lindberg P, Larsson A and Nielsen BS: Expression of plasminogen activator inhibitor-1 urokinase receptor and Laminin $\gamma 2$ chain is an early coordinated event in incipient oral squamous cell carcinoma. Int J Cancer 118: 2948-2956, 2006.

14. Ono Y, Nakanischi Y, Ino Y, et al: Clinicopathologic significance of Laminin-5 $\gamma 2$ chain expression in squamous cell carcinoma of the tongue. Cancer 85: 2315-2321, 1999.

15. Ono Y, Nakanishi Y, Gotoh M, Sakamoto M and Hirohashi S.: Epidermal growth factor receptor gene amplification is correlated with Laminin-5 $\gamma 2$ chain expression in oral squamous cell carcinoma cell lines. Cancer Lett 175: 197-204, 2002.

16. Richter P, Bohmer FD, Hindermann W, et al: Analysis of activated EGFR signalling pathways and their relation to Laminin-5 $\gamma 2$ chain expression in oral squamous cell carcinoma (OSCC). Histochem Cell Biol 124: 151-160, 2005.

17. Franz M, Hansen T, Richter P, et al: Complex formation of the Laminin-5 $\gamma^{2}$ chain and large unspliced tenascin-C in oral squamous cell carcinoma in vitro and in situ: implications for sequential modulation of extracellular matrix in the invasive tumor front. Histochem Cell Biol 126: 125-131, 2006.
18. Anneroth G and Hansen LS: A methodologic study of histologic classification and grading of malignancy in oral squamous cell carcinoma. Scand J Dent Res 92: 448-468, 1984.

19. Bryne M, Nielsen K, Koppang HS and Dabelsteen E: Reproducibility of two malignancy grading systems with reportedly prognostic value for oral cancer patients. J Oral Pathol Med 20: 369-372, 1991.

20. R Development Core Team: A language and environment for statistical computing. Ed. R Foundation for Statistical Computing, Vienna (Austria) ISBN 3-900051-07-0, URL http://www.R-project.org, 2005.

21. Frank E Harrell Jr: Design Package. R package version 2.0-12. URL: http://biostat.mc.vanderbilt.edu/s/Design, 2005.

22. Patel V, Aldridge K, Ensley JF, et al: Laminin- $\gamma 2$ overexpression in head-and-neck squamous cell carcinoma. Int $\mathrm{J}$ Cancer 99: 583-588, 2002.

23. Lim SC, Zhang S, Shii G, et al: Predictive markers for late cervical metastasis in stage I and II invasive squamous cell carcinomas or the oral tongue. Clin Cancer Res 10: 166-172, 2004. 